\title{
The Research on Effectiveness of Communicative Language Teaching in China
}

\author{
Bao'e Song ${ }^{1}$ \\ ${ }^{1}$ School of Economics and Management, Shaanxi University of Science \& Technology, Xi' an, China \\ Correspondence: Bao'e Song, Shannxi University of Science and Technology, Xi'an, 710021, China. Tel: \\ 86-186-2924-5622. E-mail: songbaoestrive2008@hotmail.com
}

Received: May 25, 2018

Accepted: July 16, 2018

Online Published: November 14, 2018

doi:10.5539/ach.v11n1p1

URL: http://dx.doi.org/10.5539/ach.v11n1p1

\begin{abstract}
Since China initiated Communicative Language Teaching (CLT) practice, it has enjoyed increasing popularity amongst educational practitioners as well as professional researchers. This paper undertakes an in-depth and all-around analysis of pedagogical practices of English class so as to ascertain the feasibility and effectiveness of CLT in China. Although China's educational system is centrally-controlled, the top-down intervening policy of CLT fails to improve students' interactive competence. Due to the contextual constraints including excessive class size, limited class hours, Confucian heritage culture, teacher equalizations as well as norm-referenced assessment, current situation of English Language Teaching (ELT) nevertheless is far from aligning with the tenet of CLT. This paper reveals that direct transfer of western-originated CLT practice is infeasible and ineffectual without considering the specific contextual factors in China and doomed to be a failure. Based on this argument, a combination of traditional pedagogy and CLT with an eclectic and dichotomous perspective is proposed and recommended to put into practice in the hope of adapting CLT paradigm to the particular Chinese contexts.
\end{abstract}

Keywords: China, CLT, communicative competence, ELT, effectiveness

\section{Introduction}

With respect to the emphasis of language acquisition, there are two disparate proposals involved in the area of linguistics. One pays significant attention to linguistic competence advocated by Chomsky while the other stresses the importance of communicative competence developed by Hymes (Liu 2008). From the perspective of Hymes (1971, cited in Her, 2008) communicative competence constitutes the following: formal possibility, implementational feasibility, contextual appropriacy, and the performative role of utterances. Considering that Hymes' conception of competence is more comprehensive than Chomsky's, communicative competence has been embraced and promoted by a considerable number of scholars and researchers. Based on the notion of communicative competence, CLT came into being in the late 1960s in the Great Britain (Richards \& Rodgers, 2001) and further spreaded into other parts of the world. Ever since its inception, CLT has enjoyed increasing popularity and further been adopted as a dominant educational paradigm on a global scale.

In terms of English language education in China, it has been influenced by the conception of CLT as well. According to $\mathrm{Yu}$ (2001), effort of introducing CLT to China was first undertaken by Li Xiaoju and her associates, who composed Communicative English for Chinese Learners, a series of communicative English books in 1979. Following Li, numerous scholars in the field of English teaching has espoused the adoption of CLT in China. However, it was not until 1990s that significant progress was made in employing CLT to the practice of English teaching in China. "In 1992 the State Education Development Commission (SEDC) replaced the 1981 structure-based national unified syllabus with a new one that set communication as the teaching aim" (Zhu, 2017). The newly compiled syllabus requires teachers to teach communicatively and develop students' overall ability with listening, speaking, reading and writing all involved. Although the official advocation of CLT has a certain positive bearing on English language teaching (ELT) in China, the current situation of ELT nevertheless is far from realizing the purpose of improving students' communicative competence. 


\section{A Historical and Theoretical Background of CLT}

\subsection{Communicative Competence}

Scholars and linguists hold different viewpoints as to what acquiring a language majorly entails. Among various perspectives, Chomskyan and Hymesian notion of competence have exerted substantial influence in the area of ELT. In the view of Chomsky, competence in language involves "the speaker-hearer's knowledge of his language in an idealized language community, under idealized psychological conditions and under idealized personal conditions of the language user" (1965, cited in Kohli, 1989). By and large, Chomsky's perspective of competence is predicated on the separation of linguistic knowledge from socio-cultural factors and psycholinguistic base. As Richards and Rodgers (2001) claim, the concentration of Chomskyan linguistic theory majorly falls upon "abstract abilities" of speakers enabling them to construct grammatically valid sentences in a language. In other words, the Chomskyan notion of competence predominantly attaches importance to linguistic competence.

The narrowness of Chomskyan description of competence has engendered numerous criticisms from linguists and scholars. Among a considerable objection towards Chomskyan perspective of competence, Habermas and Dell Hymes are influential figures who have direct bearing on the creation of the conception of communicative competence. Habermas (1970, cited in Kohli, 1989) points out that Chomskyan notion of competence suffers from inadequacy in the sense that it is "a monological capacity" and "elementaristic". As a supplement to Chomsky's linguistic competence, he proposes a notion of communicative competence which "should be related to the system of rules generating an ideal speech situation, not regarding linguistic codes that link language and universal pragmatics with actual role systems" (Kohli, 1989).

Although Habermas suggests the conception of communicative competence prior to Hymes, the creation of the term "communicative competence" generally is attributed to Hymes. In his paper "Competence and Performance in Linguistic Theory' published in 1971, he coined this term "communicative competence" (Zhou \& Yin, 2005). In contrast with Chomsky's theory of competence, Hymes considers linguistic ability is just part of language learners' communicative competence and he calls on attention for situations where "cultural knowledge is required for the interpretation of the illocutionary force of an utterance" (Kohli,1989). Her (2008) summarizes that Hymes incorporates "formal possibility", "implementational feasibility", "contextual appropriacy" and "the performative role of utterances" into his definition of communicative competence. More specifically, in Hymes's view, communicatively competent language users are supposed to possess knowledge and ability for language in terms of:

whether (and to what degree) something is formally possible, whether (and to what degree) something is feasible in virtue, whether (and to what degree) something is appropriate (adequate, happy, successful) in relation to a context in which it is used and evaluated, whether (and to what degree) something is in fact done, actually performed, and what its doing entails. (Hymes, 1972, cited in Richards \& Rodgers, 2001).

Hymes's conception of communicative competence is further articulated and reformulated by his following scholars. A pedagogically significant articulation of communicative competence is undertaken by Canale and Swain. They (1980, cited in Richards \& Rodgers 2001) categorize communicative competence into four dimensions: "grammatical competence" which is related to leaner's grammatical and lexical capacity, "sociolinguistic competence" which refers to an understanding of the social settings where communication takes place, "discourse competence" which is involved with the ability to organize language into different kinds of cohesive and coherent text, and "strategic competence" which deals with communicators" ability to initiate, terminate, develop and repair communication. In comparison with Chomsky's abstract grammatical knowledge perspective of competence, Hymes's communicative competence and the reformulation of his notion by Canale and Swain provide a more comprehensive picture of what acquiring a language entails. Therefore, the notion of communicative competence receives a considerable amount of agreement and favor from scholars and is further put into ELT practice by applied linguists and education practitioners.

\subsection{Employment of Communicative Competence-CLT}

When the notion of communicative competence is put into pedagogical application, CLT came into being. The origins of CLT can be traced back to British language teaching in the late 1960s when the theoretical assumptions of its precedent teaching method-Situational Language Teaching began to be questioned (Richards \& Rodgers 2001). Since its inception in Britain, CLT subsequently gained rapid adoption and dissemination on a global scale. As Bjorning-Gyde, Doogan and East (2008) indicate that "CLT is the dominant model for teaching English as a foreign language (EFL)" and has enjoyed an axiomatic status. 
Richards and Rodgers (2001) maintain that CLT is best regarded as an approach rather than a method. That is to say, CLT is not a method per se, but it is based on a wide range of principles that reflect a communicative view of language and language acquisition. Different scholars approach CLT from different perspectives. One of the best known definitions of communicative language teaching is provided by Nunan (1991, cited in Her, 2008) who suggests that CLT attaches importance to communication in the target language through introducing authentic texts into learning situation, providing opportunities for learners to focus on the learning process itself and making attempt to combine classroom language learning with language activities outside of classroom. Garton and Grave (2017) define CLT as an teaching approach with meaningful communication as its ultimate goal while Barrot (2018) considers CLT as a way of teaching in which the utilization of "communicative activities and target language aims to develop learners' competence of understanding and exchanging different ideas, behavioral modes, values, beliefs and cultures.". Although the definitions provided by scholars vary, it appears that they all stress the essence of CLT as genuine communication rather than simply learning such linguistic knowledge as vocabulary, grammar and structure of a language. In Yim's words (2016), the aim of CLT is to foster the capacity of individuals to create and construct utterances (spoken and written) which have the desirable social value or purpose.

\section{A panorama of CLT in China}

\subsection{The Introduction and Development of CLT}

Ever since English was stipulated as a compulsory subject by Ministry of Education, government authorities, educational institutions and students have attached increasing importance to the learning of English. However, with respect to which methodological practice can best suit China's particular context and improve students' competence most effectively has been a highly-contentious and much debated topic. Before the inception of CLT in China, grammatical-translation teaching approach is widely adopted and dominated the area of EFL teaching (Wang, 2003). According to Yu (2001), the first attempt of the adoption of CLT in China was made by Li Xiaoju as well as her colleagues, who wrote a series of communicative English textbooks--Communicative English for Chinese Learners in 1979. Furthermore, the first article supporting the adoption of CLT composed by Li was published in ELT Journal in 1984 and has exerted profound influence on Chinese teachers' perception of CLT (Yu 2001). Although the effort of scholars like Li has, to a certain extent, contributed to scholars' understanding and the spread of CLT in China, CLT has not been widely known until 1990s.

It is not until the year of 1992 that educational authority realized the importance of improving students' communicative competence and made efforts to spread the adoption of CLT in China. As Yu (2001) observes, the State Education Development Commission (SEDC) replaced previous "structure-based national unified syllabus" with a functional one with the intention to advocate communicative and interactive way of teaching. In the same year, in collaboration with the British Longman, the SEDC published a series of communication-oriented textbooks (Jin, 2007). The stipulation of communicative competence as pedagogical aim by the authoritative body SEDC has exerted a certain influence on the acceptance of CLT as teaching practice. In order to further strengthen educational institutions and practitioners' notion of communicative competence, Ministry of Education made further effort in January 2004 by issuing College English Curriculum Requirements which stipulates that "the objective of College English is to develop students' ability to use English in an all-round way, especially in listening and speaking, so that in their future work and social interactions, they will be able to exchange information effectively through both spoken and written channels..." (Meng, 2009). All these afore-mentioned efforts made by authoritative bodies are conducive to the adoption of CLT in China.

Because of China's centrally-controlled educational system, it seems plausible to assume that this top-down intervening policy should be effective and valid in improving students' interactive competence. However, due to the contextual constraints in China, the pedagogical reality paints a different picture from the authoritative bodies' intention. In the following part of this article, particular factors which have constituted considerable obstacles and constraints of the implementation of CLT in teaching practice will be presented and critically analyzed.

\subsection{The Constraining Factors of Implementing CLT in China}

First and foremost, the large number of students within a class imposes the greatest hindrance on the application of CLT. According to the statistics of the survey undertaken by the National College English Committee, the number of students in a class averages 80 in 2005 (Meng, 2009). A number of scholars and researchers such as Yu (2001), Huang (2007), Jin (2007), Hiep (2007), Meng (2009) and Wei (2018) unanimously identify large-class size as a significant factor which prevents the effective implementation of CLT. Scholars' concern about the great student number in a class is tenable and valid, considering the extreme difficulty of engaging a large class in communicative activities. In terms of such typical communicative activities as group work, role-play and 
pair-work, it is not hard to imagine the chaotic situation of a class when conducting communicative tasks. As is described by Ma (2009), the situation of a communicative class is active with students "leaving their seats to complete a task". On the condition that the conservative number of students in a class averages 60 , it appears reasonable to argue that it is almost impossible to put CLT into practice in China.

The difficulty in implementing CLT caused by large-sized classes is further complicated by the limited contact hours between lecturer and students. Typical English classes in colleges of China can be described as follows: "4 class hours a week, 18 weeks a term” (Wu, 2001). By and large, a class hour comprises 45 minutes. As Jin (2007) succinctly summarizes, every single student can maximally speak less than 1 minute when at least 50 students and only 45 minutes in one English class is the case. In light of the tenet of CLT, students should be actively engaged in all kinds of different communicative activities and conduct most of the speaking cooperatively in class. Considering the contextual factors in China in terms of large-class size and limited class hours, they constitute great difficulties and barriers for implementing CLT and, to some extent, are incompatible with the principles of CLT.

Cultural constraining factor is another barrier inhibiting the application of CLT in China. The prevalent and dominant philosophical Confucianism is in conflict with the principle of CLT. Chinese students are under great and strong influence by what Bjorning-Gyde et al. (2008, p.79) term as "Confucian Heritage Culture (CHC)". Under the guidance of the Confucian concepts of learning, students are assumed to be recipients of knowledge and obedient listeners of their instructors' lecturing whereas teachers are considered as the authoritative holders of knowledge and the center of the whole class. Such an argument can be substantiated by the assertion of Bjorning-Gyde et al. (2008, p.80): the Chinese way of learning English can be depicted as "transmission" which attaches much importance to "mastery of knowledge and rote-learning of rules and meanings". Bearing Confucian hierarchical thoughts in mind, Chinese students rarely raise questions or disagreement in class even when they are unclear of the class content in order to show respect and deference towards their teachers (Zhu 2003, p.38). Furthermore, Confucian purpose of learning knowledge for "one's own sake and not for the sake of showing off" (Lee, 2000 cited in Zhu, 2003) also hinders students from expressing their viewpoints and thus they are prone to concealing their abilities from their peer students. By and large, Chinese cultural dominance Confucianism is at odds with the student-centeredness of the characteristic of CLT.

Unlike the previous scholars who identify Confucianism as a great obstacle in undertaking CLT in China, Wei (2001) voices a different viewpoint by advocating that political factor as opposed to Confucianism prevents the application of CLT in China. By negating the impact of Confucianism on English teaching and learning in China, Wei neglects to recognize that Confucianism has exerted deep-rooted and imperceptible influence on every dimension of Chinese people's life. As Yum (1994) has alleged, Confucianism was "institutionalized and propagated" by the means of formal curricula of the educational system in China and has been respected as the fundamental social and political value system for over 1,000 years. Therefore, the strong impact of Confucianism on educational system in China is unavoidable and should never be neglected. When it comes to English education which carries underlying Western sets of values, cultural conflict with CLT caused by Confucianism is more severe and apparent. Wei's assertion is uncritical and untenable from the perspective of cultural constraints in imposing CLT in China.

With the exception of constraints engendered by class population and cultural conflict, personal factor in terms of teacher qualifications is another hindrance in transferring CLT to Chinese contexts. Andrews (1983) highlights the crucial role teachers play in the implementation of CLT by revealing that materials are only be described as potentially communicative and it is teachers who ultimately determine whether teaching materials can fulfill communicative objective. He goes further to point out that demands on the teacher when conducting CLT are considerable and he therefore advocates that teachers have to be "resourceful, perceptive, self-confident and organized". An empirical study undertaken by Ansarey (2012) also reveals that English teachers' capability has an important and direct bearing on implementing CLT. However, a predominant proportion of English teachers in China hardly have a skillful command upon four basic dimensions of English-listening, speaking, reading and writing, let alone be "resourceful, perceptive and self-confident" in organizing communicative activities. As $\mathrm{Wu}$ (2001) points out, the majority of university EFL teachers in China have not received professional training for their career. Financially speaking, the low income of English teachers forces them to take a second job outside of campus (Yu, 2001) which makes the rather commanding CLT techniques quite unpopular among teachers. In Zhu's (2003) words, quite a number of ELT teachers who advocated CLT "grew frustrated, lost their enthusiasm, and returned to traditional grammar-translation."

The testing practice is also disadvantageous to the adoption of CLT in Chinese educational system. Currently, all the undergraduate non-English major students are compulsorily required to attend the nationwide, high-stakes 
English test--College English Test. According to Jin (2005 cited in Cheng, 2008), CET which comprises CET-4, CET-6 and CET-SET (Spoken English Test) is norm-referenced test. Communicative proficiency testing should be criterion-referenced rather than norm-referenced (Morrow, 1979, cited in Porter 1983). In other words, tests of language learners' communicative proficiency should take the form of criterion-referenced which intends to test whether the subject can undertake tasks as specified or not. However, in terms of CET, it is designed to assess test-takers' language capability by comparing with their fellows on a particular task which apparently goes against the basic requirement of communicative language testing. Based on the guiding principle of criterion-referenced tests, Porter (1983) further suggests that blank-filling, true/false questions, multiple choice are not appropriate tasks and should be avoided in communicative language testing. Interestingly, the overwhelmingly testing composites of CET fall into the inappropriate tasks proposed by Porter. On the basis of Zheng and Cheng's (2008) brief summarization of CET, 80\% of CET testing content, respectively, listening section, reading comprehension and cloze are all made up of choice or blank-filling items. As has been shown, CET cannot demonstrate test-takers' communicative competence. It can just be taken as an indication of students' linguistic ability.

It has been widely acknowledged that speaking ability is an integral and fundamental comprising part of communicative competence. As Zailaini, Ismail and Azhar (2018) hold, speaking activities take up 30\% of every interaction in a typical English-speaking person's everyday life. Their statement basically reveals the importance of speaking in social interaction. Nevertheless, with regards to CET, spoken tests are only accessible to an extremely small portion of test-takers with the result of CET-4 over 80 or CET-6 over 75 . As a result of the barrier of attending CET-SET, the great majority of test-takers are ruled out from the opportunity to put their speaking ability to test. Consequently, teachers tend to ignore students' speaking ability and students attach a great amount of importance to just linguistic knowledge so as to accomplish better performance in CET.

Students' performance of CET has a direct bearing on whether they can obtain their academic certificate from educational institutions and they are competitive in the job-hunting market. In the hope of getting a desirable mark in CET, students as well as teachers only undertake arduous effort in figuring out how to get high grade by capitalizing on test-taking techniques, e.g. guessing, gaining positive impression from test-marker. As Jin (2018) claims, product-centeredness still has dominance over English teaching in China and a variety of examinations have exhausted millions of teachers and students. With the considerable concentration on examinations, CLT can hardly find its way into Chinese tertiary level English education. To succinctly summarize, the time-honored testing system exerts a negative impact on the application of CLT into Chinese educational system.

\subsection{CLT is not Panacea to English Education in China}

Even since its inception in British English teaching in the late 1960s, CLT has rapidly spreaded itself into the area of English instruction almost all around the world. As Bjorning-Gyde and Doogan (2008) have recognized, CLT appears to enjoy an axiomatic position on a global scale for teaching languages. However, the universal application of CLT to language education indicated by its axiomatic status has taken no account of the importance of the particular context where pedagogy happens. Bax (2003) rightly stresses that the dominance of CLT fails to take the crucial aspects of contexts into consideration. By the same token, Wei et al. (2018) further identifies a host of contextual factors that serve as contributors to the unsuccessful implementation of CLT in China -- educational, cultural, economic, and social--arising in the transfer of CLT from ESL (English as a second language) context to China's EFL (English as a foreign language) context. Essentially, due to drastically different situational, cultural, learning and personal contexts, it is absolutely problematic to transfer a set of teaching concepts or approaches constructed in one part of the world to another without any adaptation. In the case of CLT, it is deeply embedded in Anglo-Saxon contexts and carries itself with engrained Western perspectives of education (Hiep, 2007). Consequently, duplication of CLT to the specific context of Chinese education system severely suffers from inappropriacy and is doomed to be a failure on the grounds that a variety of particular contexts in China constrains the application of CLT.

Although the majority of literature collected in this article highlight the necessity to take account of particular contexts in adopting CLT, the perspectives held by scholars are never unanimous but controversial. Liao (2004) alleges that CLT is best for China and assumes that the situational constraints (e.g. large class size and grammar-based tests) can be resolved as long as teachers realize the existence of the various constraints. In Liao's article "The need for communicative language teaching in China", he provides little corroborating evidence to support his assertion and suffers from, in Hu's words (2005), an absolutist view on the appropriacy of CLT. He fails to recognize that CLT is not universally effective. Liao also employs the successful application of CLT by a secondary school teacher to illustrate his viewpoint. Statistically, a singular case can never be utilized as 
a convincing evidence to verify an argument. In any case, Liao's advocate of "CLT is best for China" by no means bears scrutiny and is untenable.

Essentially, as has been analyzed in the previous part of this article, large-sized classes, limited contact hours, the unqualified English teachers, the impact of traditional concept on English teaching and long-established, linguistic knowledge centered testing system have concertedly refrain the application of CLT into Chinese educational institutions. When the number of students in a class totals at least 50 , it is extremely difficult and almost impossible to exert CLT without causing chaos in class. Furthermore, the limited contact hours between lecturer and students make the implication of CLT in English classroom even harder. A majority of college English teachers are creatures of traditional grammar-oriented English education and appear to unable to undertake totally new, more demanding and unpredictable CLT. They themselves cannot even undertake smoothing interaction with English-speakers, let alone assume them to organize communicative activities in class. Comparatively low payment makes college English teachers to take up part-time job to support themselves which leads the adoption of time-consuming and effort-involved CLT to a more difficult situation.

Culturally, Chinese particular context also constitutes negative influence on the implementation of CLT. Based on Confucian education concept, an English teacher is considered to be ruler, dictator, and speaker and what he or she says is always accepted without questioning. Chinese authoritative approach of teaching diametrically goes against the tenet of CLT as student-centered. Moreover, as Wei, Lin and Litton (2018) reveal, undertaking such activities as games or interaction in Chinese culture will be regarded as entertainment as opposed to approaches of teaching. As has been presented, cultural factors definitely constitute great hindrance to CLT in China.

Traditional linguistic knowledge based testing system is another considerable barrier to the implementation of CLT in China. Whether the nationwide, high-stakes College English Test has promoted English education in China has been a much-debated and controversial topic, CET by no means is compatible with the tenet of CLT. Based on the conception of communicative competence, the essence of CLT is to improve language learners' overall ability which comprises grammatical competence, discourse competence, sociolinguistic competence and strategic competence. In the case of CET, it appears to largely assess students' grammatical competence and partially their discourse competence in the writing section. According to Gu and Liu's (2005) empirical study, it can be shown that CET is invalid in the sense that CET cannot serve as an objective indication of test-takers' communicative competence. As Wang (2003) neatly points out, due to the "magic rod"-CET in China, EFL attach much emphasis on test-taking techniques rather than fostering students' communicative competence. Generally speaking, CET has engendered test-oriented teaching in universities and has negative washback on the implementation of CLT.

\subsection{The Discrepancy between Teaching Realities and CLT}

Because of the various barriers in the particular contexts of China, the prevalent English teaching practice is still dominated by grammar, lexical and syntactic centered approach of teaching although the authoritative body of State Education Development Commission (SEDC) stipulated the purpose of the English education to foster students' communicative competence early in the 1990s. Arguably, a communicative teaching classroom is supposed to be made up of listening, speaking, reading and writing. However, the English teaching practice in China paints a drastically different picture. By and large, English education at the college level in China is characterized by intensive reading drill which comprises the following contents the passage itself, the new words and expressions listed bilingually, and the exercises measuring the students' comprehension of the text as well as their grasp of such language points as key words and sentence patterns" (HZ. Wang, 2003). H.Z. Wang's assertion is corroborated by another scholar H. Wang (2008) who maintains that the majority of EFL students concentrate on reading comprehension. Among the four indispensable components of a language-listening, speaking, reading and writing, reading is considered to be in a primary or even exclusive position in the English instruction in China with speaking and writing quite often neglected.

H.Z. Wang (2003) goes further to describe a typical English class to be teachers taking up the whole teaching hours, explaining normally in Chinese the rules of grammar in details, analyzing the collocations of words and phrases and providing a large quantity of examples for students to memorize. Obviously, teacher-dominated English instruction practice is at odds with the tenet of CLT as student-centered. Moreover, although CLT does not absolutely exclude the use of native language in class, it cannot nevertheless be justifiable employing Chinese as the major education tool. As has been demonstrated, English instruction in China is typically made up of grammar and translation knowledge as opposed to communicative activities. In HZ. Wang's words, the 
majority of the current English education at the tertiary level observes the following model: "linguistically-centered, lecturing-centered and text-centered" (2003).

In terms of sociolinguistic competence, cultural knowledge and understanding are essential in improving students' communicative capability. Paradoxically, according to Zhu (2003), cultural education in relation to English-speaking countries is quite often neglected. Even though there is cultural teaching involved in class, it is only restricted to cultural knowledge level rather than cultural understanding level which is crucial in determining learners' capability of cross-cultural communication (Liu, 2008). Consequently, when Chinese students make attempts to interact with English speakers, they tend to make culturally inappropriate and unacceptable utterances which hampers effective cross-cultural communication.

Despite the existence of the top-down stipulation from State Education Development Commission to implement CLT, grammar-translation way of teaching is still the most prevalent pedagogical method in practice in China. Consequently, English learners' communicative ability is far from satisfying the standard articulated by scholars who advocate the notion of communicative competence. Ironically, English language education in China is compared to be "a kettle of water that has been boiling for more than 10 years, but never boiled" (Huang, 2001). Although students can pass CET-4 and CET-6 with high marks, they are totally at a loss when it comes to real communications. As Li (2009) and HZ. Wang (2003) concertedly reveal, English learners in China appear to be contracted with "mute-and-deaf disease" which indicates their unsatisfactory communicative ability.

\section{Conclusion}

Chinese authoritative body's policy-making of the implementation of CLT all through the tertiary level college does not seem to be blame-worthy. If not, at least the intention of making attempts to improve English learners' communicative competence is justifiable. However, there is substantial discrepancy between the intended effect by authority and the pedagogical reality in China. The underlying reasons for this ironic mismatch between reality and intention can be attributed to the absence of the corresponding assistance from authority. Chinese government unilaterally assumes that Chinese education is centrally controlled; teachers have to abide by whatever policy the authority makes. The stipulation of the CLT by Chinese educational authority essentially provides English teachers a conundrum which defies resolution. From the perspective of top-down educational policy, English teachers have to follow the command from central government. Paradoxically, the educational realities make their flouting of authority's instruction unavoidable. Specifically, take the large-class size and the limited contact hours for instance, Chinese authority simply make decision in theory to adopt CLT, but it fails to recognize the considerable difficulties in undertaking CLT posed by the extremely small average time each student have if a class averages 50 students and 45 minutes. Under the current educational condition in China, even if teachers intend to teach communicatively and interactively, it is impossible without actual authoritative assistance.

Another contextual and actually constraining factor which policy makers take no account of is the undesirable influence of the deep-rooted traditional culture on the implementation of CLT resulting from Chinese people's attitude towards class, role of teachers and students. Virtually, the intrinsic tenet of CLT of student-centered orientation is in conflict with the thousands of years of cultural inheritance with teachers being authority over class and students. Educational policy-maker disregards the ingrained influence of thousands years of cultural heritage on Chinese people's thought system and simply assume that governmental policy can be effective enough to reverse the traditional cultural trend. Ironically, the teaching reality seems to prove the underestimation of the impact of cultural influence by educational policy-makers to be extremely flawed.

The nation-wide, high-stakes English test-CET has exerted undesirable impact upon the practical utilization of CLT. By and large, students' academic performance, especially mark on such crucial test like CET, is regarded as an indication of their comprehensive capability and the degree of their competitive edge in labor market. With respect to teachers and schools, the passing rate of CET has a direct bearing on the assessment of teachers' teaching ability and educational institutions' prestige and even ranking. Under such great stakes pertaining to CET, students, teachers and colleges invest much of their time and effort in attempting to gain better performance of CET. Problematically, as has been analyzed in the preceding part, CET cannot be taken as a communicative proficiency test on the ground that its testing contents majorly are confined to linguistic aspects of English as opposed to four overall competences. Under such circumstances, even if students, teachers and colleges are zealous about improving learners' communicative competence, they cannot afford such undesirable consequences incurred as inability to get graduating certificate for students, degrading reputation for teachers and colleges.

Due to the grammar-translation teaching approach in practice, Chinese learners' English ability at best can only fulfill Canale and Swain's grammatical competence and discourse competence. In terms of strategic competence 
and sociolinguistic competence, Chinese students' performance is far from satisfaction. With much attention focusing on CET, students hardly make efforts to improve their spoken and listening ability. Consequently, although students can pass CET-4 or even CET-6, they can barely open up their mouth to communicate with English-speakers.

Based on the analysis and evidence presented above, it can be drawn that direct duplication of Western-originated teaching approach--CLT without taking consideration Chinese specific contextual factors is infeasible and inevitably meets great undercurrent of objection and flouting of educational authority's intention by teachers. As a result of the incompatibility of China's particular contexts with the notion of CLT, the traditional grammar-translation teaching method is still lingering or even prevalent in Chinese pedagogical practice even though State Education Development Commission (SEDC) stipulated public universities to adopt CLT. Consequently, Chinese students' communicative competence, to a large extent, has not been improved and still remains at the stage of "mute-and-deaf" English.

\section{Recommendations}

Teaching approaches should be context-dependent. When it comes to the direct transfer of CLT to Chinese contexts, it meets with considerable difficulties which gives out the message that direct duplication is infeasible and corresponding adaptation is of crucial significance to make CLT exert its underlying influence on Chinese students' communicative competence. There are two alternatives as for making CLT and Chinese particular contexts compatible. One is transformation of CLT so as to make it suitable for Chinese contexts while the other one is adaptation of Chinese contexts to suit the paradigm of CLT. Specifically, such previously discussed contextual factors as educational environment, personal factors, culture and nation-wide English test all need to be fully and closely assessed and further adapted.

As Hiep (2007) suggests, CLT should not be taken as a range of "formulaic, prescriptive" classroom practices. Conversely, it is more rational and productive to approach CLT with an open-ended perspective so as to achieve its paradigm shift from a context to another. In this particular aspect, numerous scholars such as $\mathrm{Hu}(2005)$, Jin (2007), Huang (2007) unanimously propose that an eclectic approach should be adopted which conveys the message that CLT can be effectively combined with traditional grammar-translation teaching method in Chinese contexts.

Although severe criticisms have been leveled at grammar-translation method of teaching for its pure linguistic stance, it nevertheless does not rule out its function in improving students' grammatical and linguistic competence. In terms of Chinese contexts with English as a foreign language, a solid grammatical and semantic foundation is of central importance to English learners. However, English instruction can not only be confined to grammatical knowledge, communicative elements should be incorporated into syllabus design as well. Intensive conduction of communicative activities appears to be unrealistic considering Chinese contextual constraining factors but arrangement of several classes as communicatively as possible is practically feasible.

Alternatively, Chinese contexts can be adapted to the paradigm of CLT. With respect to large-sized class and limited time, it is apparently beyond the power of English teachers to change this teaching problem in China. This difficulty in implementing CLT should be brought to educational authorities' attention. It is their responsibility to take corresponding actions such as constructing more classrooms, employing more teachers, allocating more time for English education if more efficient teaching outcomes are intended. Admittedly, large student population is not an issue which can be tackled overnight. Nevertheless, teaching condition would be more appropriate for CLT if educational authorities can gradually reduce student number step by step in a class.

It is challenging to transform people's traditional concept about education under the influence of Confucianism but it does not deny the possibility to soften the clashes between the tradition and the tenet of CLT. Although it is far too demanding to shift Chinese education from teacher-centered to student-centered instantly, yet students can be encouraged to participate class discussion and voice out their opinions by their teachers. Moreover, the deep-rooted conception of regarding communicative activities as entertainment rather than as approach of teaching should be gradually changed through disseminating scientific knowledge of teaching methods to students and parents.

The nation-wide, high-stakes English test has been widely identified as negative influence force on CLT. Thus, it is urgently necessary to reform CET. First and foremost, as Gu and Liu (2005) espouse, CET should be constructed as a criterion-referenced rather than a norm-referenced test. More specifically, students should be judged according to the required standards of the College English Syllabus as opposed to their position in a norm-referenced group. Moreover, speaking test as an indispensable testing part of learners' language capability has long been left out in CET for the majority of test-takers. In order to raise students' awareness of improving 
their oral ability, spoken test should be made accessible for every test-taker rather than a privilege for those students with excellent performance in CET. In terms of the testing content, the proportion of subjective items should be improved at the same time reducing the percentage of such objective ones as multiple choices, wrong-or-right questions in order to avoid test wiseness. The ultimate purpose is to convert CET into a communicative proficiency test so as to match with the paradigm of CLT.

Currently, students' passing rate of CET has a direct bearing on teachers' annual assessment and appraisal for schools' prestige and ranking. The stakes involved in CET put teachers and educational institutions under great pressure to the extent that their focus has been wrongly shifted from improving students' genuine language ability to the teaching of test-taking tricks. Consequently, the cancellation of employing the passing rate of CET as a criteria to judge teachers as well institutions appears to be a sensible way to divert their attention from solely passing CET to acquiring solid English communicative ability.

\section{References}

Andrews, S. (1983). Communicative language teaching-some implications for teacher education. In K. Johnson \& D. Porter (eds), Perspectives in communicative language teaching (pp. 127-132). Academic Press, London.

Ansarey, D. (2012). Communicative Language Teaching in EFL Contexts: Teachers Attitude and Perception in Bangladesh. ASA University Review, 6(1), 61-78.

Barrot J. (2018). Exploring the Implementation of Communicative Language Teaching in the Philippines: A Tertiary Teachers' Perspective. Social Science Electronic Publishing, 12(3), 5-12.

Bax, S. (2003). The end of CLT: a context approach to language teaching. ELT Journal, 57(3), 278-287.

Bjorning-Gyde, M, Doogan, F \& East, M. (2008). Towards a fusion model for the teaching and learning of English in a Chinese Context. In D. Lee \& W. Michelle (eds), Teaching in transnational higher education (pp.77-87). Routledge, New York.

Brandl, K. (2008). Communicative language teaching in action: putting principles to work. Washington, DC: Pearson Education.

Cheng, L. (2008). The key to success: English language testing in China. Langugae Testing, 25(1), 15-37.

Garton, S, \& Grave, K. D. (2017). An analysis of three curriculum approaches to teaching English in public-sector schools. Language Teaching, 50(4), 441-482.

Gu, W. P., \& Liu, J. (2005). Test analysis of college students' communicative competence in English. The Asian EFL Journal Quarterly, 7(2), 117-132.

Her, J. H. (2008). Communicative language teaching and outcomes-based objectives setting: a questionnaire-based survey of a sample of tertiary teachers of English in Taiwan. Journal of Maori and Pacific Development, 9(2), 79

Hiep, P. H. (2007). Communicative language teaching: unity within diversity. ELT journal, 61(3), 193-201.

Hu, G.W. (2004). English language education in China: policies, progress, and problems. Language Policy, 4(1), $5-24$.

Hu, G. W. (2005). CLT is best for China'---an untenable absolutist claim. ELT Journal, 59(1), 65-68.

Huang, K. S. (2007). Reconsideration on CLT in college English: theory and practice. Canadian Social Science, $3(1), 87-90$.

Jin, Y. (2007). Adapting communicative language teaching approach to China's context. Sino-US English Teaching, 4(10), 29-33.

Jin S. F. (2018). Ways to Cultivate Intercultural Communicative Competence in College Foreign Language Teaching. Journal of Hubei Correspondence University, 5, 216-220.

Kohli, V. (1989). The communicative approach to language teaching theoretical limits. New Delhi, ND: Reliance Publishing House.

Li, B. L. (2009). Processed-centered teaching and its implications in English teaching in China. English Language Teaching, 2(1), 24-29.

Li, S., \& Li, F. (2004). Intercultural communicative language teaching: rethinking the communicative approach to ELT in China. EA Journal, 22(1), 20-43.

Liao, X. Q. (2004). The need for communicative language teaching in China. ELT Journal, 58(3), 270-286. 
Liu, J. X. (2008, June). Some ideas on culture teaching in Chinese. The VATME Newsletter (pp. 3-7).

Liu, Y. (2008, June). A study of language teaching from a sociolinguistic perspective of communicative competence. Canadian Social Science, 4(3), 80-86.

Ma, Q. H. (2009). Key elements in conducting communicative approach to language teaching. Canadian Social Science, 5(2), 46-55.

Meng, F. S. (2009). Encourage learners in the large class to speak English in group work. English Language Teaching, 2(3), 219-224.

Porter, D. (1983). Assessing communicative proficiency: the search for validity. In J. Keith \& P. Don (Eds.), Perspective in communicative language teaching. Academic Press, London.

Richards, J. C., \& Rodgers, T. S. (2001). Approaches and methods in language teaching (2nd ed.). New York, NY: Cambridge University Press.

Wang, H. (2008). Probing EFL students' language skill development in tertiary classrooms. English Language Teaching, 1(2), 3-6.

Wang, H. Z. (2003). Current conditions of college English teaching-problems and measures. In M Li, HF Hua \& JZ Zhang (Eds.), Aspects of English language teaching and research. Su'Zhou, SZ: Su'Zhou University Press.

Wang, Y. Q. (2003). Exploring the dominance of the grammar translation method over EFL teaching: views from China. In M Li, HF Hua \& JZ Zhang (Eds.), Aspects of English language teaching and research, Su'Zhou, SZ: Su'Zhou University Press.

Wei, D. D. (2001). Communicative language teaching and Confucianism in China and Taiwan. In AARE 2001 Conference Papers, Conference of the Australian Association for Research in Education (pp.1-11). Melbourne, Australia.

Wei, L, Lin, H. H., \& Litton, F. (2018). Communicative Language Teaching (CLT) in EFL Context in Asia. Asian Culture and History, 10(2), 1-9.

Wilkins, D. (1983). Some issues in communicative language teaching and their relevance to the teaching of languages in secondary schools. In J. Keith \& P. Don (Eds.), Perspective in communicative language teaching. London, LON: Academic Press.

Wu, Y. A. (2001). English language teaching in China: trends and challenges. TESOL Quarterly, 35(1), 191-194.

Yim, S. Y. (2016). EFL young learners: their imagined communities and language learning. ELT Journal, 70(1), 30-37.

Yu, L. M. (2001). Communicative language teaching in China: progress and resistance. TESOL Quarterly, 35(1), 194-198.

Yum, J. O. (1994). The impact of Confucianism on interpersonal relationships and communication patterns in East Asia. In A. Larry \& E. Richard (Eds.), International communication: a reader (pp.75-86). California, CA: Wadsworth Publishing.

Zailaini, M. A., Ismail, W., \& Azhar, A. N. M. (2018). Strategies on Promoting Students to Communicate in Communicative Language Teaching of Arabic Classroom. Advanced Science Letters, 24(1), 172-174.

Zheng, D. G., Humphreys, G., \& Hamp-Lyons, L. (2004). Understanding successful and unsuccessful EFL students in Chinese universities. The Modern Language Journal, 88(2), 229-244.

Zheng, Y., \& Cheng, L. (2008). College English Test (CET) in China. Sage, 25(3), 25-30.

Zhou, X. C., \& Yin, H. L. (2005). On roles and features of context in CLT. Canadian Social Science, 1(1), $108-111$.

Zhu, H. M. (2003). Globalization and new ELT challenges in China. English Today, 19(4), 36-41.

Zhu, Y., \& Shu, D. (2017). Implementing foreign language curriculum innovation in a Chinese secondary school: An ethnographic study on teacher cognition and classroom practices. System, 66, 100-112.

\section{Copyrights}

Copyright for this article is retained by the author(s), with first publication rights granted to the journal.

This is an open-access article distributed under the terms and conditions of the Creative Commons Attribution license (http://creativecommons.org/licenses/by/4.0/). 